\title{
MODES OF AUTHORITY AND SOCIAL CHARACTER RESEARCH
}

\author{
DANIEL BURSTON \\ Duquesne University
}

Social Thought \& Research, 1998, Vol. 21, No. 1-2

The relationship between prevailing patterns of authority and social character formation was once a major topic for theory and research, but has fallen into relative neglect of late. This paper elucidates Fromm's three modes of authority, their psychoanalytic and sociological antecedents, their intrinsic strengths and limitations, and their possible application to contemporary' sociological issues.

\section{A. Modes of Authority in Psychoanalysis}

Freud's attitude toward paternal authority and its role in religion and culture was profoundly ambiguous, and invites multiple readings. In 1910, for example, Freud attributed Leonardo Da Vinci's astonishing precosity as an engineer and natural scientist to the fact that he had "escaped being intimidated by his father in earliest childhood", thereby linking the exercise of paternal authority to the habitual suppression of free and unfettered intellectual development in children, and later on, in adults. At this stage, Freud implied that rebellion against paternal authority may be an emancipatory process.

However, three years later, in Totem and Taboo, Freud linked the tendency to rebel against paternal authority with an intractable Oedipal ambivalence that is supposedly rooted in our phylogenetic inheritance, which underlies underlies the "collective obsessional neurosis" he thought he found at the heart of religious dogma. On this reading, rebellion against authority is an unconscious re-enactment of a collective rebellion against a prehistoric tyrant that had long since lost any rational or adaptive function - is, in short, a repetition compulsion, rather than a progressive or emancipatory 
rebellion against paternal authority, or even acknowledged their existence in his work (Burston, 1994, p. 214)

At the outset, Freud attracted disciples who responded to the critical elements in his thought. However, those who were most radical and uncompromising in their opposition to patriarchal authority were eventually thrown out of the IPA, and dismissed, 1909. Williger 1909. Wilhelm Reich in 1933 and Erich Fromm in 1946

Though acknowledged by Freud as a thinker of great promise in 1907. Otto Gross was basically an anarchist with strong irrationalist leanings. Through his contact with Ludwig Klages and Stephan George's circle, Gross became immersed in the matriarchal theory of J.J.Bachofen, and an ardent critic of patriarchal authority (Michaels, 1983, chapter 2). Following Gross, who first broached the subject in 1916, Wilhelm Reich expounded also on the sado-masochistic or "patriarchalauthoritarian" character a decade later (Cattier, 1970, chapters 9 $\& 10$ ). However, unlike Gross, who distrusted science, Reich argued for the existence of rational and irrational authority in a way that paralleled Freud's tendency to equate religion with irrationality and science with rationality per se.

Like Gross, Reich, and the earlier Freud, Fromm thought that the ruthless repression of childhood sexuality is one way in which the patriarchal-authoritarian character reproduces itself (Fromm, 1947. pp. 155-156). Unlike them, however, Fromm did not privilege the repression of childhood sexuality in his theory of character and social character, nor believe that sexual liberation, so called, would inevitably dissolve structures of irrational authority in the individual, the family or society at large (Fromm,
1955, pp.148-149; Fromm1992, p. 88).

Moreover, while Reich discussed two different modes of authority. Fromm distinguished between three different types, which may co-exist in one and the same culture, or indeed, in one and the same person, and whose consequences for human development are exceedingly diverse. If Fromm was right, then respect for authority (or its opposite) means utterly different things depending on whether we are refering to rational, irrational or anonymous authority (Fromm, 1941, chapter 4, section 1; Fromm, 1947; Fromm, 1955).

\section{B. Authority in Fromm and the Frankfurt School}

Fromm's modes of authority are always discussed in conjunction with an analysis of social character, which typically includes wide ranging historical tableux, economic and anthropological research, and probing reflections on theology and mass culture at various periods of Western history (and prehistory). Fromm shared this discursive, interdisciplinary approach with other members of the Frankfurt School, whose studies of authority, like Reich's, focused on the cultural, religious and economic roots of fascism. In Horkheimer's case, they were rooted in a critical appraissal of Freud's theory of culture and religion, which Horkheimer later dropped, but which Fromm retained and augmented when he finally severed ties with the Institute (Jay, 1973, chapters $3 \& 4$ ).

A paper of this length cannot do justice to all of Fromm's formulations, nor explore their manifold interconnections with the early work of Horkeheimer, Marcuse. Benjamin, Lowenthal and others. Even listing Fromm's formulations in serial order, identifying their main characteristics, and the points at which they appear and reappear, develop, atrophy or disappear in his life's work, and why, is out of the question here - though it would furnish the basis for an absorbing doctoral dissertation. sometime.

However, for purposes of our present inquiry, we must venture some broad generalizations. First, not all of Fromm's analyses and assertions regarding authority and social character types are backed up by empirical data or field research. And this is not grounds for reproach. After all, a twentieth century researcher can never interview a neolithic tribesman, a Pharisee, a medieval artisan or theologian, a Renaissance potentate or a Protestant Reformer to judge their attitudes toward gender roles, parenting. civil disobedience, foreigners and so on. To glean what their attitudes and unconscious orientation were, we can only interrogate their texts and artifacts, and make inferences from their contemporary descendents or near-analogues in rustic settings, as a cultural anthropologist might compare contemporary Bedouin clans with ancient Hebrew herdsmen.

Obviously, we cannot dismiss this body of work as "merely speculative" or of purely antiquarian interest. On the contrary, Marx's historical materialism and Max Weber's historical sociology are both built on theoretical foundations like these, 
and those who do empirical social research can still glean inspiration and insight from Fromm's non-empirical analyses, even as they make their own methodologies and instruments more precise, focused and relevant to contemporary issues and circumstances. Furthermore, a desire to engage Fromm's nonempirical social character research might act as a useful corrective to viewing the dynamics of social character primarily through narrowly "presentist" lenses.

A second point is that Fromm's historical and theoretical constructions that are unsupported by actual field data attend closely to economic processess, but focus equally on the meaning of religious beliefs and dogmas and their corresponding notions of authority, in the apparent conviction that these both reflect and reinforce existing social character, and herald or promote incipient transformations of social character in response to burgeoning economic and technological developments. (This was also consistent with the Frankfurt School approach.)

By contrast, most neo-Frommian research on social character focuses on technological and economic factors to the manifest neglect of religion and authority as both mirrors of and formative factors in the fortunes of decaying or emergent social character formations. This shift in emphasis reflects the decline of organized religion and the increasing secularization of the modern (and "postermodern") worlds. However, the world-wide resurrgence of religious fundamentalism, right wing extremism, white-supremacist movements and our never-ending proliferation of weird, apocalyptic cults suggest that rekindling interest in these areas may provide insight into some of the more bizarre and inhuman events of our times, which will shape future history in the course of the 21st century.

A third point is that one of Fromm's modes of authority, namely, anonymous authority, is supposedly a creature of modern market conditions, and presumably irrelevant to or of marginal importance in pre-capitalist societies. Its relatively recent appearance, according to Fromm, should make it amenable to socio-analytic research. However, despite the importance he attributed to it, in theory, Fromm never studied it empirically. I suspect this negelct was inadvertent, or a product of the circumstances that drew him to Mexico, and away from the United States. Or perhaps Fromm felt that the middle-class
American life furnished such abundant proof of his arguments that rigorous research was utterly unnecessary.

In any case, the fact remains that Fromm's studies of German workers in the Weimar Republic (Fromm, 1984), and of Mexican peasants in Chiconcuac (Fromm \& Maccoby, 1970), do not address anonymous authority or its offspring - or perhaps its sibling - the marketing character. Moreover, in social character research since 1970 - in English, at any rate -- discussions of 列 and marketing character, with which it was closely allied -- for Fromm, at any rate - has become controversial, more on which momentarily.

A fourth point worth noting is that Fromm's analysis of rational and irrational authority in pre-capitalist and early capitalist societies is rooted in his evolving theory of matriarchy and

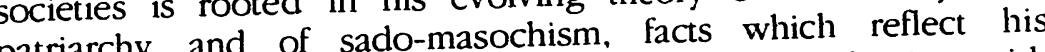
embededness in a Freudo-Marxist discourse that begins with Otto Gross, evidently, and continues to this day (e.g. Wolfenstein, 1993). However, after 1936 it is also increasingly intertwined with burgeoning discussions of alienation and idolatry, of rational

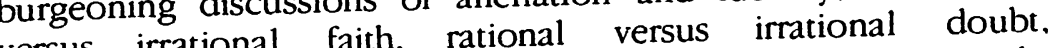
humanistic versus authoritarian conscience and existential needs. which run throughout his later work. A schematic overview of this body of work (beginning with Escape From Freedom) yields the following orientations or syndromes.
Rational Authority promotes

(Syndrome A)

Love, Independence

Rational Faith

Rational Doubt

Humanistic Conscience

Solidarity

Self-realization
Irrational Authority

promotes

(Syndrome B)

Sado-masochism (symbiosis)

Irrational Faith

Irrational Doubt

Authoritarian Conscience

Obedience

Idolatry, alienation
Note that I have not included matriarchy and patriarchy in this schematic bifurcation, because Fromm associated the negative attributes of the patricentric "complex" with irrational authority, atcicic orientation with anonymous and those of the matress a little later. Meanwhile, let's review 

what actually Fromm means by rational and irrational authority
before going any further.

Rational authority is a relationship between two (or more) people of unequal age, experience or status. For the sake of discussion, let us elaborate on Fromm's prototype of the masterstudent relationship (Fromm,1941, p. 186). In his (or her) field of expertise, the master is authorized to set goals and standards that the student must strive to achieve as a result of his (or her) training or experience. But in principle, at any rate, rational authority aims at minimizing or indeed abolishing differences in status, so that master and pupil can potentially relate as equals in the fullness of time.

Meanwhile, the achievement of such equality presupposes effort, respect and discipline on the student's part. In order to master a skill or a body of learning, the pupil must follow the master's instructions, and practice diligently. Obedience of this kind entails a commitment, not to the teacher qua teacher, but to the craft or discipline, and the goal of becoming but to the practitioner in one's own right. And ideally, the teacher derives satisfaction from the student's progress, because it confirms knowledge and ability - Erikson the event that the of knowledge and proficiency the or exceeds the master's level presumably contained and the friction of competing egos is craft that they both share.

To summarize, then, rational authority is based on competence experience and mutual respect, and entails the possibility of equality, and perhaps, indeed, of friendship, depending on circumstances. By contrast, irrational authority is designed to perpetuate or intensify conditions of inequality through the use of force, or the threat of force, and/or the use of deception, secretiveness and/or the manipulation of interpersonal relationships. The prototype for this, as Fromm observed, is the master-slave relationship, where the "discipline" demanded by irrational authority is really a form of bondage that benefits the authority himself (ibid). Though it is often disguised as benevolent paternalism, such authority is really motivated by greed, fear and/or the desire to dominate and humiliate others. Irrational authorities habitually distort the truth, and feel threatened by the prospect of equality, though they often enjoy a kind of sordid intimacy others -- sado-masochism or symbiosis to alleviate their loneliness and to consolidate their hold on power. In this context, obedience to authority entails a lack of respect for oneself, although this trait of character need not be conscious, particularly if it is accompanied by neurotic pride and/or compensatory tendencies to idealize the master. Conversely, defiance of irrational authority may be a healthy attempt to sunder the bonds of oppression that masquerade as paternalistic or disinterested care and guidance.

As Fromm noted in The Sane Society (1955) and again in The Art of Loving (1956), rational authority is similar in character to conditional or fatherly love, and is as vital to the development of an alive and intact human being as is unconditional (or motherly) love. Parenthetically, it is interesting to note how this analytically-derived typology differs from Max Weber's distinction between charismatic and beauraucratic authority. Weber's notion of charismatic authority is analogous to Fromm's irrational authority, but without invariably being oppressive. On the contrary, it is often experienced as liberating, at least initially. In some respects, Weber's notion of the routinization of charisma and the emergence of bureaucratic authority resembles Fromm's notion of rational authority, but lacks its incipiently positive. emancipatory thrust, issuing ultimately in an "iron cage" that is anti-life, and by virtue of its anonymity, also analagous to anonymous authority, more on which momentarily.

A more detailed and discerning analysis of the resemblances and disparities between Weber and Fromm is called for elsewhere. For now, suffice it to say that Fromm saw no "down side" to rational authority, as Weber did, and that Weber's notion of charismatic authority was modelled historically on the thought and example of Otto Gross, who rebelled vigorously against a deeply authoritarian father (Michaels, 1983).

Meanwhile, as Fromm freely conceded, rational and irrational authority are not entities per se, but heuristic abstractions or typological fictions which are seldom encountered in "pure" form (1941, p. 188). So applying these schemata in a naive or dogmatic way can do more harm than good. A good example of this shortcoming can be found in Theodor Adorno's study. The Authoritarian Personality. Fromm reproached Adorno for failing to distinguish between the authoritarian (or proto-fascist) mentality and what he and Maccoby refered to - somewhat confusingly - as the "traditional-authoritarian" type found chiefly in peasant societies. The "traditional-authoritarian", they noted, is a productive hoarding type - hard working. 
resourceful, religious and proud. These peasants are generally suspicious of less traditional, more enterpreneurial (i.e. exploitative) types, and often scornful of their less industrious (i.e. receptive) counterparts, who are prone to immersion in culture of drunkeness and violence (Fromm \& Maccoby, 1970).

In Social Character in A Mexican Village, Fromm and Maccoby noted that while traditionalists enjoin obedience to authority for survival's sake, unlike authoritarians, they are not sadists (ibid). They do not enjoy or admire the wanton excercise of force, or derive pleasure from inflicting suffering or humiliation on others. Indeed, Fromm's scathing remarks about Adorno's study center chiefly on his insensitivity to this issue and its manifold implications. To Fromm's rejoinders I would add that traditionalists also tend to value a truth loving disposition, while authoritarians regard truth - and other people - as expendable, if it interferes with their personal or political agendas (Burston,
1991 , pp.110-116).

Other factors were also in play, however. In The Legacy of Erich Fromm, I noted that Adorno's conflation of authoritarian and traditionalist sensibilities may have been partly attributable to the waning population of "traditional- authoritarians" in the United States, and to his one dimensional view of organized religion as an anti-democratic force in society (ibid). The construction and scoring of the F-scale evince a tacit equation between strong ties to organized religion and anti-democratic tendencies that is simplistic and misleading, but not without precedent in analytic circles. Freud did not distinguish between rational and irrational authority as such, but like any follower of the Enlightenment, stressed that science is rational while religion is irrational. And in the same spirit, as noted previously, Reich argued explicitly that religious authority is irrational, while scientific authority is inherently rational and democratic.

In effect, then, Freud and Reich made their characterizations of authority depend solely on the content of a belief system, i.e. whether or not it encompasses belief in God and the supernatural. Fromm, by contrast, made his modes of authority hinge on the mode of relatedness that emerges between master and pupil (or parent and child), i.e. whether the authority actually promotes independent judgement and initiative, shuns violence, secrecy, manipulation and lies, etc., regardless of his/her belief in God (or lack of it). Accordingly, Fromm acknowledged the existence of rational and irrational authority in both the scientific and the spiritual domains -- and rightly so, think. But his refusal to embrace the invidious dichotomy which Freud, Reich and Adorno espoused does not nullify the existence of what I've termed Syndrome A and Syndrome B, and the fact that the "traditional- authoritarian" type combines elements of both syndromes in a paradoxical synthesis I'll call Syndrome C. At the risk of oversimplification, we'll sketch its salient features as follows.

Traditional-authoritarianism promotes (Syndrome C)
Positive Traits

Industrious, disciplined

Self-reliant

Proud
Non-sadistic

\section{Negative Traits}

Not terribly generous

Insular, wary of strangers

Resistant to change

Defers to Authority
In The Legacy of Erich Fromm, I argued that the term "traditionalist-authoritarian" should be replaced with the simpler term "traditionalist", so that this mentality, which leans more toward Syndrome A, is contrasted more effectively with the authoritarian type, who is unambiguously centered in Syndrome B. I still hold this view.

Moreover, I still maintain that the agrarian traditionalist needs to be clearly differentiated from the capitalist conservative and/or the religiously oriented neo-traditionalist (or often, perhaps, the pseudo-traditionalist ), who espouses traditional or "family" values while embracing free-market principles and ideologies. Nineteenth century liberal economic policy, that goes by the name of "fiscal conservativism" nowadays, inevitably destroys traditional societies, where the rate of technological change and development is invariably quite slow. Moreover, and more to the point, perhaps, it totally reverses the relationship of embeddedness between society and the market that obtains there. Taking a cue from Ferdinand Tonnies, Karl Polanyi observed that in pre-capitalist societies, the market is always embedded in and regulated by society and tradition. Unfettered capitalism reverses this situation, by embedding social relations in the exigencies of the market, to the inevitable detriment of the common good (Polanyi, 1944; Polanyi. 1968). As a result, spheres of human activity and social interaction where norms of conduct were once semi-independent of market considerations, like medicine, education, the arts, even sports, become dominated - 
and inevitably, debased - by adherence to the proverbial bottom line.

\section{Anonymous Authority and Critical Thinking: Fromm E Asch}

Though Fromm never said so in quite so many words, rational and irrational authority engage those affected by them in a more or less personal manner. This view is supported by Fromm's tendency to contrast anonymous authority not with rational or irrational authority per se, but with what he called external or olert authority, i.e. authority vested in a specific person. As Fromm noted in Escape From Freedom:

In external authority is clear that there is an order and who gives it; one can fight against the authority, and in this fight personal independence and moral courage develop. But whereas in internalized authority the command, though an internal one, remains visible, in anonymous authority both command and commander have become invisible. It is like being fired at by an invisible enemy. There is nobody and nothing to fight back against (Fromm, 1941, p.190).

Unlike external authority, where differences in power, knowledge and status are freely acknowledged, and sometimes rigidly insisted upon, anonymous authority - which Fromm sometimes called invisible or alienated authority - is diffusely present in groups of nominal equals, and is mediated by rumor, "common sense", public opinion and the impersonal structures of bureaucratic roles and procedures. As a result, anonymous authority is not backed up by overt demands, or by threats and coercion. It runs on the principle of conformity, not of obedience, though the lack of genuine solidarity and relatedness among group members that results feeds a pervasive fear of being isolated, or merely different.

The impersonal, levelling character of anonymous authority, and the consequent obstacles to identifying and defying it, render it different from the other two modes. But like them, Fromm suggests, it is socialized in growing children by the example and the expectations of parents and teachers, for whom the group functions as a kind of collective censor or superego, even though people are nominally free to think or act independently. To sustain the illusions of freedom, individualism, and equality in a conformist milieu, the gap between ideology and practice must be bridged by self-deception and rationalization, with a corresponding decline in the capacity for rational doubt (Fromm, 1941, chapter 7).

Fromm first discussed anonymous authority in 1941, and noted Fromm first discussed anon mentality, was the socially patterned that this, and not the fascist mentality, was the sociacies. While preferable defect characteristic of industrial democracies. While preferable
to fascism, of course, it still erodes our capacity to think critically. By critical thinking, Fromm meant the capacity for rational doubt, and not intelligence as measured by I.Q. tests. According to Fromm, a person can be highly intelligent, I.Q.wise, and still lack the ability to question or consider matters deeply, freed from conventional prejudices and beliefs. In fact, Fromm noted, highly intelligent people generally come up with Fromm noted, highly intelligen reality than less intelligent people cleverer reasons for distorting reality than less intelligent people do. Intelligence as measured by conventional methods has litte to do with the ability to reason critically. It may be a critical hindrance. The first and primary prerequisite of critical
reasoning is an emotional willingness to question prevailing beliefs and practices, which requires the courage of conviction and a willingness to court disapproval or punishment (Fromm,1955, pp.64-66, pp.152-155).

Fromm was not alone in his concerns. As Solomon Asch demonstrated immediately after World War II, anonymous authority really does erode a person's judgement. Asch wanted to determine what percentage of the general population were to determine what independent judgement in 1949. Accordingly, he set up a situation where an experimental subject was invited into a room with ten or so others (who were colluding with the experimenter), and then asked to declare which of two lines on a graph was closer in length to a third line which the on the same graph. This was in length, even for someone whose was visibly closer to another in length, even for someone whose vision was slightly impaired. Nevertheless, Asch's confederates had been instructed beforehand to falsify their replies, and say that the other line was longer, and were called on to answer before the test subject was.

To the astonishment of Prof. Asch, $80 \%$, or 4 out of 5 , falsified their responses in keeping with the majority's perception of events. Only $20 \%$ - or slightly less, as he later confided to me proved capable of defying the group consensus and stating the lengths of the lines accurately, and many of those who did disagree with the majority were visibly distressed as a result. Asch reasoned that, consciously or unconsciously, the vast 
majority of middle Americans circa 1950 allowed their judgement to be biased by prevailing attitudes and perceptions, and were therefore incapable of exercising independent judgement (Asch,1956). To avoid anxiety, they literally took leave of their senses rather than experience or express rational doubt about the prevailing consensus, even though many of them, as patriotic Americans, would no doubt have espoused an conscious attitude of robust individualism. This is exactly how Fromm described the effects of anonymous authority (Burston, 1994, pp.151-154)

\section{Anonymous Authority and the Marketing Character}

Fromm's discussion of anonymous authority in Escape From Freedom predates his depiction of the marketing character by six years. But Man For Himself leaves little doubt that the two phenomena are intertwined. In Man For Himself, Fromm cited Karl Polanyi's observation that the modern market is not a place of meeting , a place where producers and consumers generally know each other, negotiate directly, and where goods and services are appraised and exchanged in terms of their use value. In truth, the modern market is not even a place, but an utterly impersonal (though extremely sophisticated) mechanism in which commodities and services are bought or traded on the basis of their exchange value, which is determined by the vagaries of fashion, of chance and the machinations of multinational conglomerates (Polanyi, 1944).

Among the various commodities bought and sold in the modern market is human labor, and in Man For Himself, Fromm stressed that anonymous authority proliferates where, regardless of their ability (or lack of it) people must market themselves aggressively to avert failure and unemployment, and where the tendencies to abstraction, quantification and alienation accompanying the headlong advance of technology promote a tendency to experience oneself and others principally as commodities, or as mere bundles of attributes that are bereft of any intrinsic value, and therefore desperately dependent on others to bestow meaning and direction to their increasingly hollow and aimless existences. Hence the term "marketing character".

By the mid 1950's, the post-War economic boom was in full swing, and some new features emerged in Fromm's discussion of anonymous authority. In The Sane Society, for example, the section on anonymous authority in chapter five is followed by a section on what Fromm called the "principle of non-frustration" section on chacterized as a debased matriarchalism in The Art of Loving and elsewhere. Henceforth, Fromm would frequently link the prevalence of Henceforth, Fronds with this anonymous authority

Reviewing these glosses on anonymous authority in sequence, then, we find that the idea is first introduced in Escape From then, we find that the marketing character, Freedom, were it is not yet linked the marketing mentality even though a constitutive element of the marketing mentality the experience of oneself as a commodity at the mercy of impersonal market forces - was already much on Fromm's mind. In Man For Himself, the link between anonymous authority and the marketing character is made evident, and by The Sane Society, is accompanied by an emphasis on the (non-productive receptive) tendencies that presumably serve to palliate the inner emptiness of the marketing personality. In short, by 1955 , Fromm claimed that marketing personality. In shomotes conformity, consumerism and anonymous authority promotes conform associated with the by implication, all the negative traits associated with the receptive and marketing orientations spelled out seven years earlier.

However, rather than rehearsing his earlier enumeration of traits in Man For Himself, in The Sane Society, Fromm took a more in authority in the community of Forest Park, Ill. Fromm gleaned his data from a story by William $H$. White entitled "The Transients", which appeared in the May through August editions of Fortune magazine in 1953. According to Fromm, the residents of Forest Park - and by implication, much of middle-class of due to lack of self-acceptance, 2) a fear of being alone, and of facing the inner emptiness occasioned by their lack of individuality and genuine relatedness to others, 3) a tendency to stigmatize privacy, or the search for privacy, as anti-social, 4) an stignatize privacy, of tastes indiscriminate sociability, 5) a low-brow standardization of tastes and opinions, issuing in anti-intellectualism, and ignorance of (or indifference to) classical music, 6) a avowed tolerance for all points of view (relativism), which masks a deeper wariness teward any deeply held convictions, and 7) a propensity for 等 interpersonal conflict through excessive and/or inappropriate 
self-disclosure (Fromm, 1955, pp. 139-147). Let us call this Syndrome D.

\section{Anonymous Authority promotes}

\section{(Syndrome D)}

Conformity

Consumerism

Negative receptive traits

Negative marketing traits

Fromm's analysis of Forest Park tells us as much about him as it does about his subject matter. Despite his clear, discursive writing style, Fromm was clearly baffled and revolted by the account of a male resident who was considered odd for expressing a vivid appreciation for Mozart's "Magic Flute", and who therefore resolved not to speak about classical music to his neighbors anymore. Likewise for a woman stigmatized by her peers after a neighbor accidentally discovered her reading Plato. Fromm was incensed at a school teacher who characterized a young child as "maladjusted" because he prefered the company of one or two close friends, or perfect solitutude, to the more gregarious and game-oriented activities of his peers. Beneath his theoretical analyses of alientation and conformity, one senses that Fromm was simply disgusted by the weird combination of cliquishness, the lack of privacy and the endless and "indiscriminate talking about one's problems" the residents indulged in, hinting that emotional voyeurism and exhibitionism en masse have usurped the place of "core to core" relatedness.

Despite some grudging concessions in Man for Himself, where he enumerated some positive traits associated with the marketing orientation, in The Sane Society, Fromm freely expressed what he really felt: that anonymous authority produces nothing of value, humanly speaking. Fromm's preference for the dignity and self-possession of the traditional-authoritarian type when he finally got around to describing it -- is too obvious to be missed. Though it registers only obliquely in his published work, perhaps, it is vividly apparent in the story Fromm told of an American tourist visiting the shop of a indigenous Mexican craftsman. The tourist liked a particular pot, and asked the artisan/proprietor how much it cost. The tourist then inquired about the cost of three, or five or ten such pots, expecting the price per pot to decline as the volume of anticipated sales increased. To his total astonishment, Fromm noted, the artisan kept raising the price, in defiance of any kind of economic rationality the prospective customer was familiar with. Puzzled and annoyed, the American left. When Fromm, who witnessed this scene, inquired why he kept raising the price, the craftsman replied that to create one such pot had been a distinct pleasure. But to make three (or more) identical pots would be extremely tedious.

Though Fromm often told this story as a joke, it is actually a pithy illustration of the different Weltanschauungen of the traditionalist and the modern marketing mentality. A contemporary American potter would doubtlessly oblige a customer like this, and be happy to do so, reasoning that each addditonal pot he sold is an advertisement for his skills in a vast, anonymous market where he has yet to meet most prospective customers. And the notion of assembly line production, if not second nature, is not foreign or anathema to him.

By contrast, his Mexican counterpart is still accustomed to selling his wares in a face-to-face market place, and knows most of his cumstomers personally. Though he isn't averse to haggling or selling to strangers, of course, the indigenous craftsman does not make profit his "bottom line", resists standardization and routinization, and generally refuses to treat himself, i.e. his labor, as a commodity. And if he is going to stifle his spontaneity to suit the arbitrary whims of a total stranger -- which is unlikely, given his conditions -- he is going to make him pay for the offense! In short, he is not primarily concerned with sales and profit, but with keeping his work alive and interesting.

Fromm's obvious affection for rustic individualists like this one bespeaks a certain affinity with Thorstein Veblen and C.Wright Mills, whose laments for the decline of the craftsman in the 20th century are accompanied by equally scathing indictments of conformity under contemporary market conditions. Without embracing the more relativistic extremes of contemporary social theory, let us acknowledge that Fromm's construction of the fruit - or the by-product - of anonymous authority, the marketing character, is partly a function of his own social character, and by implication, his own bias. This is not necessarily grounds for reproach. Fromm gave every indication of being fully conscious, even proud of his bias. 
Let us also acknowledge that Fromm's construction of the marketing type was at least partly a response to material/historical circumstances that no longer obtain. In The Sane Society, for example, he wrote:

Speaking of the economically most progressive country, the United States, the exploitation of the masses has disappeared to an extent which would have sounded fantastic in Marx's time. The working class, instead of falling behind in the economic development of the whole society share in the national wealth, and it is perfectly valid assumption that provided no major catastrophe occurs, there will, in about one or two generations, be no more marked poverty in the United States. Closely related to the increasing abolishment of economic suffering is the fact that the human and political situation of the worker has changed the human Largely through his unions, he has become a social "partner" of management. He cannot be ordered around, fired and abused, as he was even thirty years ago (p.95).

Nowadays, more than forty years after these words were written, Fromm's prediction that poverty would disappear, barring some unforseen catastrophe, seems quaint. Not only have unions and workers suffered massive setbacks and reversals, but poverty has been steadily increasing since the late 1970's, and the middle class itself is shrinking dramatically. At present, it is unclear to what extent these trends have been slowed, halted or even reversed, and how long our new won prosperity will last. But the idea that poverty will disappear or that the unions will ever recover their former power seems unlikely, to say the least.

Moreover, leaving issues like material comfort and stability aside, between 1955 and the present, the complacency and uniformity of the American middle class was rocked by the emergence of anti-War movement, the civil rights movement, the counterculture, the feminist movement and gay movements, and the ecology movement, which left indelible imprints on the collective psyche. These movements, which arose in response to socially patterned defects like militarism, racism, sexism and environmental degradation spawned their own varieties of conformism and extremism, and as a result, potentiated a powerful right-wing backlash that has dramatically reshaped the whole political terrain of the United States, and whose consequences for the twenty-first century cannot be predicted with certainty.
In any case, at present, the assertion that we live in a consumeristic culture that palliates the inner emptiness occasioned by the progressive attenuation of core to core relationships with the promise of affluence and safety is dated. It is true, as far as it goes, but by now almost everyone knows that "the system" delivers its palliatives erratically, selectively and in many cases, not at all. The question then arises - what relevance does the concept of the marketing character have to the U.S.A. today? Has it outlived its usefulness? And was it entirely accurate to begin with? The first of Fromm's students to question the realism and usefulness of the marketing concept were David Riesman (Riesman,1950) and Michael Maccoby (Maccoby,1976; Maccoby, 1981; Maccoby,1983). They argued that Fromm's depiction of the marketing type is basically moralistic, and lacks a realistic appreciation of the productive potentialities unleashed by contemporary economic conditions. Riesman, for example, conceded that deep and authentic relationships are rarer in a highly mobile, market-driven society. But marketing (or "other directed") individuals, though shallower in their emotional ties, are much more open to and tolerant of strangers in their midst than their rural counterparts and precapitalist predecessors.

This is indisputably true, and incredibly strange, if you pause to think about it. Nowadays, the stranger is less feared and reviled than was generally the case in pre-modern times. But as a result of decreased emotional involvement, our own spouses, children and close friends may be more estranged from us, and we from them. Evidence for this trend -- if any is needed - comes from the recent studies on how middle-class Americans flee the vicissitudes and anomie of postmodern family life in favor of the relative security and satisfaction of their jobs, neglecting their marital relationship and their children in the process. A similar trend can be found among the countless Webheads who find more real camaraderie in cyberspace than they do in their "real" face to face relationships. These are only some of the things one observes on the contemporary scene.

Some people find these trends benign, amusing or quirky. But they are actually frightening commentaries on the times. How does one assess these developments in a calculus of human solidarity - supposing there was such a thing? Is this a net loss or a great gain, or both, in some measure? And if both, can we really claim that societal gains in tolerance and diversity - such as they are - outweigh the loss of genuine intimacy and 
authenticity in human relations? (And if so, on whose authority?).

These are undecidable questions, whose answers are dictacted as much by one's personal experience and point of view as it is by "objective" trends. Similar issues of perspectivity bedevil us elsewhere. For example, Riesman and Maccoby both note that among urban dwellers, the growth of abstract thought - at the expense of reliance on direct, personal observation - creates a greater willingness to adapt to changing social, technological and economic realities. The idea here is apparently that adaptability is an instrinsically good thing. But is it, really? Admittedly, adaptability is vital for personal survival. And survival, in turn, is a basic and non-negotiable prerequisite for productive living. But doesn't the struggle for survival often compromise us in various ways? Are we merely making a virtue of necessity?

Fromm often noted that the way we are constrained to meet our material needs is dramatically at variance with our existential needs, and that this socially patterned discrepancy, though seldom conscious, results in the gradual atrophy of humanistic conscience and the capacity for critical thought (Burston, 1996). That being so, I suggest that adaptability is actually a neutral trait, neither good nor bad in itself, and that by assigning a positive value to it, we are also betraying a bias - one different than Fromm's, perhaps, but a bias nonetheless. Before we can judge whether adaptability is good or bad for our mental health we must first specify $u$ hat it is we are adapting too, and how we are adapting to it. Otherwise, this issue is so abstract that it becomes utterly vacuous.

Traits like tolerance and adaptability are only two of the salient characterizations in Fromm's depiction of the marketing syndrome. Consideration of other traits would raise similar questions - some merely moot, others undecidable. But wherever these reflections take us, finally, Riesman and Maccoby's rejoinders to Fromm do have some merit. At the very least, they underline the historically conditioned nature of Fromm's ideas, and put Fromm's Eurocentric bias in bold relief for our continuing appraisal and scrutiny. They also offer alternative interpretations for contemporary trends, and whether we agree with them or not, that too is a useful service. After all, Fromm brought a proud and self-consciously European perspective to bear on American social realities. Why privilege the perspective of a foreign expert, however learned, humane or perceptive, over an indigenous one? Don't both deserve an equal hearing?

Finally, Michael Maccoby has voiced a very cogent objection to Fromm's analysis of the marketing character. He notes that peasants can also be highly conformist, and not merely obedient to higher authority on pragmatic grounds. In other words, anonymous authority is also found in pre-capitalist milieus, where market norms and practices are still solidly embedded in traditional forms of life. This raises the question of whether or not conformism is simply more prevalent in the late capitalist societies than in tribal and peasant milieus or not - though testing this hypothesis in a global village, where even the remotest tribal settlements now feel the impact of the international markets in their day to day existences, might be difficult indeed.

Leaving aside the practical and financial obstacles to conducting this kind of research, which are formidable, to say the least, one way of resolving this question might be to study the structure of authority relations in our high schools and universities more carefully. The study of the individual and/or the family can only take us so far, particularly in the "information age", the so called "postmodern" era, when the overall influence of the family on individual and social character has diminished, and that of schools and the media has increased. Studying the social character of teachers is vital, of course, but so are careful in vivo observations of teacher student interactions over extended periods of time, and the way students themselves appropriate or ignore the overt and implicit messages about authority, survival and success that they get in the classroom. Universities should also be studied, because our society prolongs adolescence much longer than is biologically necessary -- indeed, healthy -- to train its workforce: a fact Fromm, for one, neglected in his analysis of contemporary alienation.

Still, if Fromm was right about the marketing character as a distinctively modern phenomenon, then the relative decline of irrational authority and the rise of anonymous authority (alongside rational authority) should be empirically observable as particlar modes of interpersonal relatedness between teachers and students at all levels of the educational system. The key is to formulate the appropriate methodology, observational techniques, and so on, and to compare different regions and social classes within the United States and Europe, and compare 
those, in turn, with schools in more "backward", authoritarian regions of the world, that are less affected by technology and global market forces.

In the absence of this kind of empirical research, we can only guess at the prevalence of marketing tendencies in the population at large. Personally, I think that marketing tendencies, though still powerful and pervasive, are probably on the wane in the U.S.A., as Micahel Maccoby suggests. One bit of evidence for this is that when Solomon Asch's conformity experiment was replicated in the late seventies and early 80 's, researchers found that fully $40 \%$ of their subjects could both experience and express rational doubt about the group's perceptions. That is double the percentage of previous sample.

While quite heartening, no doubt, the more significant finding may still be that the remaining $60 \%$ could not experience or express rational doubt in such circumstances, which suggests that the majority of Americans are still quite conformist, and frightened of excercising independent judgement. Further evidence for this interpretation can be gleaned from the response of the American electorate at that same period of history to former Presidents Reagan and Bush, whose clandestine roles in the manipulating the Iranian hostage crisis, promoting Iran-Contra dealings, and all kinds of drug-traffic and state sponsored terrorism in Guatemala, El Salvador, Nicaragua, Columbia and elsewhere in Latin America are now more or less a matter of public record. Yet at the time these events unfolded, very few Americans could bring themselves to doubt the official lies and propoganda, to "see" what was really going on, and to act accordingly.

In general, then, we need to explore whether or to what extent a market-driven form of anonymous authority gradually supplants deference to rational and irrational authority in the transition from feudal to industrial and post-industrial society, and why. The way Fromm depicts this transition gives the impression that old-fashioned particarchal authority is obsolete, because it is out of step with the spirit and requirements of an increasingly cybernetic social order. Fromm was obviously on to something important, but in his enthusiasm for his new discovery, and his distaste for what he observed, he probably exaggerated somewhat. After all, irrational authority, and its political offspring, fascism, still flourish in America, and in the most "advanced" societies, and will no doubt mushroom again if our global economic situation worsens, as it is likely too when the environment starts to deteriorate as a consequence of global warming. That being so, why was Fromm fully persuaded that old fashioned authoritarianism is becoming a thing of the past?

Prior to Fromm, the analytic literature from Freud to Reich (and beyond) focused heavily on the father imago as the locus of authority, rational or otherwise (Fromm, 1959; Fromm, 1970). Fromm evidently thought that the social transformations wrought by the decline of traditional religions, of the oldfashioned patriarchal family, the rise of consumerism, bureacracy, and so on, necessitate a new way of envisioning authority relations that mirrored emerging social relations - and rightly so, I think.

However, anonymous authority is found in pre-capitalist societies, and cannot be purely a creature of modern market conditions. Anonymous authority is evidently older than Fromm thought, though Fromm was probably right to suspect that it is profoundly intensified by prevailing economic realities. Sadly, and for that very reason, it is probably here to stay, regardless of our efforts to transform or humanize society. All the more reason to understand it better.

\section{References}

Asch, Solomon. 1956. "Studies of Independence and Conformity: I. A Minority of One against A Unanimous Majority". Psychological Monographs 70, no. 9.

Burston, Daniel. 1991. The Legacy of Erich Fromm, Cambridge: Harvard University Press.

Burston, Daniel. 1994. "Freud, the Serpent \& The Sexual Enlightenment of Children", International Forum of Psychoanalysis, vol. 3, \#4, pp. 205-219.

Burston, Daniel and Olfman, Sharna. 1996. "Freud, Fromm \& The Pathology of Normalcy". Pp. 301-353 in A Prophetic Analyst: Erich Fromm's Contributions to Psychoanalysis, edited by Mauricio Cortina and Micahel Maccoby, Northvale, New Jersey: Jason Aronson.

Cattier, Michel. 1970. The Life E Work of Wilhelm Reich, New York: Avon Books.

Fromm, Erich. [1941] 1965. Escape From Freedom. New York: Avon Books, 1965. 
Fromm, Erich. [1947] 1990. Man For Himself. New York: Henry Holt \& Co.

Fromm, Erich. 1955. The Sane Society. Greenwich, Connecticutt: Fawcett Premier Books.

Fromm, Erich. 1956. The Art of Loving. New York: Bantam Books.

Fromm, Erich. [1959] 1972. Sigmund Freud's Mission: An Analysis of His Personality and Influence. New York: Harper \& Row.

Fromm, Erich. [1970] 1971. The Crisis of Psychoanalysis: Essays on Marx, Freud and Social Psychology, Greenwich,
Connecticutt: Fawcett Premier Books.

Fromm, Erich and Maccoby, Michael. 1970. Social Character in a Mexican Village: A Sociopsychoanalytic Study, Engelwood Cliffs, New Jersey: Prentice-Hall.

Fromm, Erich. 1984. The Working Class in Weimar Germany: A Psychological and Sociological Study. Edited by Wolfgang Bonns, Cambridge: Harvard University Press.

Fromm, Erich. 1992. The Revision of Psychoanalysis, Boulder, Colorado: Westview Press.

Jay, Martin. 1973. The Dialectical Imagination, Boston: Beacon Press.

Maccoby, Michael. 1976. The Gamesman , New York: Simon \& Schuster.

Maccoby, Michael. 1981. The Leader. New York: Ballantine Books.

Maccoby, M., 1983, "Social Character versus the Productive Ideal", Praxis International, pp. 70-83.

Michaels, Jennifer. 1983. Anarchy \& Eros: Otto Gross's Impact on German Expressionist Writers, Utah Studies in Literature and Lingustics, New York: Peter Laing.

Polanyi, Karl.1944. The Great Transformation, Boston: Beacon Press.

Polanyi, Karl. 1968. Primitive, Archaic and Modern Economies. Edited by George Dalton, Boston: Beacon Press.

Reisman, David. 1950. The Lonely Crowd, New Haven, Yale University Press.

Wolfenstein, Victor. 1993. Psychoanalytic Marxism: Groundwork, London: Free Association Books.

\author{
CARL L. BANKSTON III \\ JACQUES HENRY \\ University of Southwestern Louisiana
}

Social Thought and Research, 1998, Vol. 21, 1-2

\begin{abstract}
This study suggests that the class-caste argument associated with the Wilson-Willie debate provides a fundamental line of division in theories of racial and ethnic stratification; it maintains that groups that combine minority statuses may be affected by both class and caste influences, a situation of "double jeopardy": and it describes French-speaking Louisiana blacks, or Creoles, as a group that combines minority statuses. Analysis of Census data shows that race and Louisiana French ethnicity are each related to life chances and that ethnic inequality is primarily a matter of class characteristics, while racial inequality is primarily a matter of caste characteristics. There is an interaction between ethnicity and race, however; minority ethnicity shows a weaker relationship to household income for blacks than for whites. We suggest that this may be a consequence of the relative power of minority identities.
\end{abstract}

In recent years, one of the major debates in the scholarly discussion of racial and ethnic inequality has been the extent to which this inequality is to be regarded as a matter of social class status or as a matter of caste status. William Julius Wilson, perhaps the best-known advocate of the class explanation, has argued that the subordination of minority groups was historically produced by the imposition of caste positions through racism, but that contemporary racial inequality is maintained by the socioeconomic situations of minority group members (Wilson, 1978; 1987). Charles V. Willie $(1978 ; 1979$; 1989; 1991), in response, has argued that racial inequality remains 